\title{
Repetitive Transcranial Magnetic Stimulation for Treatment-Resistant Depression: Recent Critical Advances in Patient Care
}

Camila Cosmo, MD PhD $D^{1,2}$

Amin Zandvakili, MD PhD ${ }^{1,2}$

Nicholas J. Petrosino, $M D^{1,2}$

Yosef A. Berlow, MD PhD 1,2

Noah S. Philip, $M D^{1,2, *} \oplus$

\author{
Address \\ ${ }^{*}, 1$ VA RR\&D Center for Neurorestoration and Neurotechnology, Providence VA \\ Healthcare System, 830 Chalkstone Ave, Providence, 02908, USA \\ Email: noah_philip@brown.edu \\ ${ }^{2}$ Department of Psychiatry and Human Behavior, Alpert Medical School of Brown \\ University, Providence, RI, USA
}

Published online: 11 March 2021

(C) This is a U.S. Government work and not under copyright protection in the US.; foreign copyright protection may apply 2021

This article is part of the Topical Collection on Depressive Disorders.

Keywords Major depressive disorder • Depression - Transcranial magnetic stimulation - Theta burst stimulation

\section{Abstract}

Purpose Transcranial magnetic stimulation (TMS) is an evidence-based treatment for pharmacoresistant major depressive disorder (MDD). In the last decade, the field has seen significant advances in the understanding and use of this new technology. This review aims to describe the large, randomized controlled studies leading to the modern use of rTMS for MDD. It also includes a special section briefly discussing the use of these technologies during the COVID-19 pandemic.

Recent findings Several new approaches and technologies are emerging in this field, including novel approaches to reduce treatment time and potentially yield new approaches to optimize and maximize clinical outcomes. Of these, theta burst TMS now has evidence indicating it is non-inferior to standard TMS and provides significant advantages in administration. Recent studies also indicate that neuroimaging and related approaches may be able to improve TMS targeting methods and potentially identify those patients most likely to respond to stimulation. 
Summary While new data is promising, significant research remains to be done to individualize and optimize TMS procedures. Emerging new approaches, such as accelerated TMS and advanced targeting methods, require additional replication and demonstration of real-world clinical utility. Cautious administration of TMS during the pandemic is possible with careful attention to safety procedures.

\section{Introduction}

Neuropsychiatric disorders continue to be the third leading cause of disability worldwide, with $10.4 \%$ of total global burden, measured by global disabilityadjusted life years (DALYs) [1]. Of these disorders, major depressive disorder (MDD) is associated with the greatest burden, corresponding to $2.54 \%$ of global DALYs and $3.7 \%$ of all US DALYs [2, 3]. An estimated 264 million people are stricken by depressive disorders worldwide [4]. In US adults, the lifetime prevalence of MDD was found to be $20.6 \%$, with most individuals presenting moderate or severe courses and substantial impairment [5]. These data indicate the seriousness of this mental health disorder and demonstrate the importance of developing novel and effective therapeutic approaches.

Treatment-resistant depression (TRD), or more specifically pharmacoresistant MDD, is defined as the lack of remission despite multiple (generally defined as $>2$ ) trials of a tolerable and evidencebased treatment, and is associated with significant disability. As a classic exemplar study of TRD, the Sequenced Treatment Alternatives to Relieve Depression $\left(\mathrm{STAR}^{*} \mathrm{D}\right)$ trial revealed that $63.2 \%$ did not remit following the first trial; up to a third never achieved remission [6]. Lack of effectiveness is another important issue in depression management. Effectiveness consists in $\geq 50 \%$ reduction in baseline symptom severity $[6,7]$; compared to placebo, antidepressants have an effectiveness of up to $30 \%$. This figure is even lower when the outcome under investigation is remission, defined as meeting threshold criteria on standard rating scales [8]. Based on these data, current TRD treatment usually features various augmentation strategies, such as using mood stabilizers and/or antipsychotics, which also results in polypharmacy, with potential interactions and associated safety concerns.

One novel approach to TRD management over the last decade is repetitive transcranial magnetic stimulation
(rTMS). This was cleared by the US Food and Drug Administration (FDA) for patients with pharmacoresistant depression in 2008. rTMS is a non-invasive brain stimulation procedure that applies repeated magnetic pulses over the scalp to generate an electrical current in the cortex, provoking electrophysiological effects that modify the neural excitability in the target area and correlated brain networks $[9,10,11 \bullet \bullet, 12]$. Its safe profile (particularly lack of systemic side effects associated with pharmacotherapy), cost-effectiveness, and better focality are some of its advantages over other neuromodulation techniques, such as electroconvulsive therapy [13-17].

Early work suggested the antidepressant effects of rTMS were exclusively related to modulation of left and right dorsolateral prefrontal cortex (DLPFC) excitability [18-22], based in theory that depression resulted from hypoactivation of the left prefrontal region and increased activity in the right DLPFC $[23-27,28 \bullet$. With a progressive understanding of the pathophysiology of depression and contribution of intrinsic connectivity networks to depression [2932], functional mapping was applied in later trials to investigate neural mechanisms underlying TMS therapeutic effects [33-35]. This work reported changes in brain regions distal to the site of stimulation, such as the thalamus and amygdala, and indicated that the therapeutic mechanism of action is related to polysynaptic (i.e., "downstream") effects [36, 37].

Although numerous trials have now demonstrated the effectiveness of rTMS monotherapy or augmentation [20, 22, 38-41], not all findings have been robust [42-44], and important questions persist regarding optimal use. We reviewed and summarized the most recent findings of randomized rTMS clinical trials for pharmacoresistant depression, addressing the optimization of parameters, potential neurophysiological biomarkers, and ongoing areas of research such as emerging neuromodulation techniques. 


\section{Technical aspects of TMS}

rTMS is a non-invasive approach to modulate neural circuitry using electromagnetic fields. By running an alternating electrical current through a coil placed on the scalp of the patient, a focal and fluctuating magnetic field is generated which, in turn, induces an electrical current (following Faraday's law). This induction occurs primarily in the cortical grey matter neurons of the underlying target region. When these currents are run rapidly and in succession, they comprise the magnetic "pulses" of rTMS, with each pulse achieving a peak magnetic field strength of $\sim 1.5$ Tesla [45]. The target region, most commonly the DLPFC for depression, is the area of cortex where the induced electrical field is maximal, and successful targeting depends on accurate surface placement of the TMS coil and coil geometry. One of the greatest challenges in targeting derives from a fundamental property of coil design: greater depth, achieved by larger dimensions of a coil, results in a less focal electrical field [46•]. While the figure- 8 coil design, the most commonly used coil in clinical TMS, significantly improved focality, the so-called depth-focality trade-off remains an important limitation with depth of stimulation around $2-3 \mathrm{~cm} \mathrm{[47].}$

Several parameters define rTMS, including frequency, intensity, train duration, intertrain interval, and session total. Frequency refers to the number of magnetic pulses delivered over time expressed in Hertz. While high-frequency TMS at $10 \mathrm{~Hz}$ targeting the left DLPFC has long demonstrated efficacy [20, 48], low frequency $(1 \mathrm{~Hz})$ targeting the right DLPFC and bilateral TMS have also been shown to be effective $[49,50 \bullet \bullet$. Stimulation intensity is expressed as a percentage of the motor threshold, i.e., the minimal amount of energy delivered to the primary motor cortex that is required to elicit a motor response typically in the contralateral hand (called the motor threshold). A "train" is a series of pulses. Train duration refers to the amount of time in which a series of pulses are delivered. Intertrain interval refers to the time between trains. Lastly, session total is the number of pulses delivered in a single session. In clinical TMS for TRD, patients most commonly receive $10-\mathrm{Hz}$ stimulation to the left DLPFC at an intensity of $120 \%$ of motor threshold with 4 -s trains and 26-s intertrain intervals for 3,000 pulses. Standard sessions last $37.5 \mathrm{~min}$ and a treatment is 5 days per week for 4-6 weeks. These settings mimic those used in the pivotal studies described below, although recent work indicates that slightly shorter intertrain intervals are effective. [51] Still, the optimal parameters for treatment are not completely understood and other types of TMS have evidence for use in pharmacoresistant depression. For example, theta burst stimulation (TBS) delivers pulses at $50-\mathrm{Hz}$ triplets repeated at $5 \mathrm{~Hz}$ in 2-s trains every $10 \mathrm{~s}$, parameters designed to mimic the endogenous theta rhythm of hippocampal pyramidal neurons [52 $\bullet$. Recently shown to be non-inferior to TMS in the treatment of depression [53], TBS is a promising development as it offers sessions that last $<10 \mathrm{~min}$, decreasing patient burden and improving cost-effectiveness.

\section{TMS studies}

To date, there are seven TMS systems cleared for use in TRD: NeuroStar, BrainsWay (H1-coil), MagVenture, CloudTMS, Apollo, Nexstim, and Magstim. Since 
October 2008 (when TMS was first FDA cleared), over 360 studies investigating the application of TMS in depression have been published. Among those, there are more than 150 trials and 47 meta-analyses, with 29 randomized clinical trials (RCTs) and 7 meta-analyses specifically addressing individuals with TRD. The studies selected for the current comprehensive review include the state-ofthe-art in the field, in addition to relevant RCTs published in the last two decades addressing the effects of TMS in the modulation of depressive symptoms.

Pioneering works

In 1995, George et al. performed the first trial to examine the clinical application of rTMS. In this pilot study, six patients with TRD (five of whom had bipolar disorder) received at least five consecutive sessions of rTMS (80\% motor threshold [MT] [54]; 800 stimuli at $20 \mathrm{~Hz}$ cycles), applied over the left prefrontal cortex. One patient remitted and clinical improvement was observed in another. Interestingly, the only remission was observed in the individual with unipolar depression. Given the design restrictions and its small sample, the conclusions were limited, but suggested rTMS was well-tolerated with potential antidepressant properties. This initial observation was confirmed by more robust trials [38, 39], including a large multisite double-blind, sham-controlled randomized clinical trial [20]. Notably, prior to this pilot trial, two other studies have addressed transcranial magnetic stimulation antidepressant effects, but both consisted of case reports and had applied single pulse TMS [55, 56].

O'Reardon et al. conducted a pivotal double-blind, randomized, shamcontrolled, multisite study, including 301 antidepressant-free individuals with MDD who had failed at least one antidepressant [48]. The authors found that, when compared to sham, rTMS applied to the left DLPFC safe and effective for TRD. This trial, sponsored by Neuronetics (NeuroStar TMS Therapy System, Neuronetics Inc., Malvern, PA, USA), was the foundation of the initial FDA clearance for TMS use in pharmacoresistant major depression. The stimulation protocol consisted of five TMS sessions per week, repetition rate of $10 \mathrm{~Hz}$, applying $120 \%$ of MT, 3000 pulses per session, for 4-6 weeks (acute treatment phase), followed by a 3-week taper period. Symptom improvement was observed at 4 weeks (17-item Hamilton Depression Rating Scale: $p=.006$; and 24item (HAMD24): $p=.012$; Montgomery-Asberg Depression Rating Scale (MADRS): $p=.038$, with post hoc correction for baseline score imbalance) with an even more significant clinical response (HAMD17: $p=.005$; HAMD24: $p=.015$ ), and remission rates (outcomes for active vs. sham; MADRS: $14.2 \%$ vs. $5.2 \%$, HAM-D $17: 15.5 \%$ vs. $7.1 \%$, HAMD $24 ; 17.4 \%$ vs. $8.2 \%$ ), at the end of 6 weeks of intervention, except for MADRS $(p=.052))$. Furthermore, rTMS was proven to be safe and well tolerated, with side effect-related dropout rate as low as $4.5 \%$, without reports of serious adverse events such as seizure or death [48]. Results from this study were replicated by a multisite NIMH-sponsored study, which found comparable response, remission, and safety outcomes [20].

In the first large, naturalistic study of TMS, Carpenter et al. investigated the effectiveness of rTMS in TRD in a multisite study [57]. Three-hundred seven individuals were treated using parameters used in $\mathrm{O}^{\prime}$ Reardon et al., applied over 
the left DLPFC in the majority of the patients (i.e., 208 subjects), with a few exceptions when a sequential bilateral stimulation or right-sided rTMS was chosen when nonresponse was seen following left-sided application. In addition to completing the acute phase treatment, $86.3 \%$ (265 subjects) of the original sample joined a 52-week follow-up study, also using a naturalistic approach.

During the acute course, patients had on average 28.3 (SD=10.1) rTMS sessions, consisting of 42 days ( $\mathrm{SD}=14.2)$, resulting in significant improvement in depression symptoms and severity as shown by the (a) Clinical Global Impression-Severity scale (CGI-S) - change from baseline to endpoint $(p<.0001)$, response rate $58.0 \%$, and remission rate $37.1 \%$; (b) Inventory of Depressive Symptomatology, Self-Report (IDS-SR)—response rate $41.5 \%$, and remission rate 26.5\%; and (c) 9-Item Patient Health Questionnaire (PHQ9 )-response rate $56.4 \%$, and remission rate $28.7 \%$. Only one major adverse event was documented. A sleep-deprived patient, who was on sertraline, bupropion, and dextroamphetamine/levoamphetamine, had one seizure in her 10th session, likely due to a lower seizure threshold in the setting of multiple contributors. This study confirmed what had been seen in prior large controlled trials $[20,48,58-60]$, namely that rTMS is safe, is well tolerated, and is an effective treatment for TRD.

Despite multiple trials showing the effectiveness of rTMS for TRD [20, 22, 3841], modest findings or even lack of effect has been observed [42-44]. Within this context, questions have arisen about whether more modest effects of rTMS are associated with less brain penetration (see section above describing the depth/focality trade-off) [61]. As an attempt to expand the amount of stimulated tissue, the H-coil was developed with the aim of modulating deeper brain regions, creating a new rTMS modality referred to as "deep" transcranial magnetic stimulation (dTMS) [62]. The H-coil allows stimulation of somewhat deeper cortical layers and wider brain areas, as demonstrated in mechanistic studies [63, 64]. Levkovitz et al. carried out the first trial to evaluate the safety and effectiveness of dTMS in TRD [61]. Sixty-five subjects were randomly assigned to four different arms (with all groups receiving 1,680 stimuli at $20 \mathrm{~Hz}$, per session): (a) H1-coil, 120\% MT, predominantly stimulating the left prefrontal cortex; (b) H2coil, 120\% MT, inducing bilateral stimulation; (c) H1L, 120\% MT, applied specifically over the left PFC; and (d) H1L, 110\% MT, left PFC. After tapering the antidepressants for 2 weeks, patients completed 4 weeks (20 sessions) of active dTMS, with no sham. Depression symptoms improved significantly in those assigned to dTMS at $120 \%$ MT (all $p<.001$ ), with more robust findings observed in those submitted to unilateral stimulation (H1-coil, response rate: 47\%; remission: 42\%; H1L-120\%, response rate: 60\%; remission: 50\%), when compared to bilateral (H2-coil group, response rate: $30 \%$; remission: $10 \%)$. Over half of participants attended a follow-up assessment at 3 months, and reported sustained improvement. No major adverse events or cognitive impairments were observed, and these findings led to FDA clearance of the H1-coil system (Brainsway Deep TMS Therapy System, Jerusalem, Israel) in January 2013. Later, the same research group conducted a large double-blind randomized shamcontrolled multicenter trial that confirmed the efficacy, safety, and prolonged effects of dTMS [65]. 
Whether one particular coil design can produce superior results is an important and unanswered question for the field. To compare the safety and antidepressant efficacy of rTMS applied using a figure-8 coil vs. an H1-Coil, Filipčić et al. performed an industry-independent randomized controlled trial, and found no differences in remission rates between the two coils (all $p>.1$ ) [66]. They reported higher response rates with dTMS ( $p=.04)$, although both modalities yielded remission rates that are typically higher than those reported in other studies. Regardless, the comparable remission outcomes provide empiric support that clinical outcomes are more likely associated with the "downstream" or polysynaptic effects of TMS, which may be independent of the devices used.

Theta burst stimulation is novel and so-called second-generation rTMS modality $[67,68]$. It was initially investigated as a neurophysiologic tool as described above, with its primary differentiating factor being that it can modulate synaptic plasticity with effective results in a very short period of time (typically 3-10 min for an entire "dose," compared to the standard 37.5 min required for an rTMS session) $[68,69]$. The first human study to TBS, performed by Huang et al., included delivery of short bursts of a high-frequency $(50 \mathrm{~Hz})$ TMS, repeated at intervals of $200 \mathrm{~ms}(5 \mathrm{~Hz})$, at 80\% MT, in three different patterns (intermediate TBS (imTBS); continuous TBS (cTBS); and intermittent TBS (iTBS)) [67]. iTBS was found to yield electrophysiological changes in the motor cortex when administered as intermittent (iTBS; $2 \mathrm{~s}$ train, repeated at 10s) or continuous (CTBS; 40s train of uninterrupted stimulation); stimulation yielded robust long-term potentiation (iBTS) or long-term depression (CTBS)-like activity. This led to the first randomized controlled trial of TBS for depression by Li et al. [70]. They randomized sixty patients with TRD to four groups-(a) CTBS, (b) iTBS, (c) a combination of cTBS and iTBS, and (d) sham TBS, with 15 patients per group. All patients received 2 weeks of stimulation, and they found that depression improved in all groups, but those who received iTBS consistently demonstrated superior outcomes.

The largest study of TBS to date was performed by Blumberger et al., who conducted a large randomized multisite non-inferiority trial to compare iTBS versus rTMS [53]. In this trial $(n=404)$, patients received up to 30 treatments of $10 \mathrm{~Hz}$ rTMS (120\% TMS, at $10 \mathrm{~Hz}, 3,000$ pulses/session, duration: $37.5 \mathrm{~min}$ ) or iTBS (120\% MT, $50 \mathrm{~Hz}$ bursts, at $5 \mathrm{~Hz}, 600$ pulses/session, duration: 189 s) over the DLPFC. Statistically significant response and remission rates were detected in the iTBS group (HRSD-17-reduction from baseline to endpoint: 10.1 points; response rate: $49 \%$; and remission: $32 \%$ ), as well as in the $10 \mathrm{~Hz}$ rTMS group (HRSD-17-reduction from baseline to endpoint: 9.9 points; response: 47\%; and remission rate: $27 \%$ ), confirming the study hypothesis that iTBS was non-inferior to $10 \mathrm{~Hz}$ rTMS in improving depressive symptoms. In regard to safety, headache was the most prevalent adverse event, with no differences in side effects and tolerability between groups [53]. This trial led to FDA clearance of iTBS for TRD.

Stimulation laterality is an important and understudied area in rTMS research. TRD rTMS protocols have predominantly employed three different protocols: (a) unilateral high-frequency rTMS (HF-rTMS, $\geq 5 \mathrm{~Hz}$ ) targeting the left DLPFC; (b) unilateral low-frequency rTMS (LF-rTMS, $1 \mathrm{~Hz}$ ) to the right DLPFC; and (c) 
bilateral, by sequentially applying HF-rTMS to the left and LF-rTMS to the right DLPFC [20, 71-74]. All these modalities appear superior to sham [20, 71-74], yet studies comparing these protocols have produced differing outcomes. Analogous results in regard to depressive symptoms improvement were observed in studies evaluating left (HF-rTMS) vs. right stimulation (LF-rTMS) [72, 73], and bilateral stimulation has generally not been shown to be superior to unilateral rTMS $[27,75,76,77 \bullet \bullet]$. However, in a network meta-analytic approach, Brunoni et al. indicated bilateral rTMS might be more effective compared to HF-rTMS $(\mathrm{OR}=4.02 ; 95 \% \mathrm{CI}=1.3-12.35)[78 \bullet \bullet]$. Interpretation of this finding is mitigated by issues related to network meta-analyses, where interventions can be contrasted yet never prospectively tested against each other. Recently, evidence has emerged that supports the idea of equivalence between left HF-rTMS and right-sided LFrTMS from Berlow et al. [79]. This is an area of important inquiry as LF-rTMS devices are considerably less expensive and could be made more portable to address patient needs during the pandemic (see COVID19 section, below).

Durability of rTMS-related antidepressant effects is also an important consideration. The long-term effects of rTMS were assessed in a year-long follow-up study [80], revealing a sustained response as shown by the clinical outcomes: (a) CGI-S-change from end of acute phase to endpoint ( $p=.0269$ ), response rate $67.7 \%$, and remission rate $45.1 \%$; (b) Inventory of Depressive Symptomatology, Self-Report (IDS-SR) - response rate 44.1\%, and remission rate 29.3\%; and (c) 9-Item Patient Health Questionnaire (PHQ-9)-response rate 60.7\%, and remission rate $37.0 \%$, with response/remission rates at 12 months endpoint similar to acute outcomes. After completing acute rTMS, $36.2 \%$ of subjects required at least 1 additional rTMS session over the period of 1 year, with an average of 16.2 sessions (SD=21.1). Sixty-two and a half percent of 120 individuals, who responded or remitted following the acute course, remained responsive in all the assessments (at 3, 6, 9, and 12 months). No serious adverse events were observed. In addition to validating prior findings on rTMS effectiveness and safety, this study showed that rTMS yields durable effects in TRD patients and that patients can respond to retreatments. Additional studies have shown similar findings, endorsing its long-lasting benefits [81, 82].

\section{Emerging interventional techniques}

In the past two decades, interventional psychiatry has advanced significantly, resulting in the emergence of innovative neuromodulation techniques. Groundbreaking trials have investigated the application of these techniques in several neuropsychiatric disorders with promising results. Particularly in treatment-resistant depression, novel approaches have been explored. Preliminary data has indicated the potential effectiveness of transcranial direct current stimulation (tDCS) [83-85], magnetic seizure therapy (MST) [86-89], transcranial photobiomodulation (t-PBM) with near-infrared (NIR) [90, 91], and transcranial focused ultrasound (tFUS) [92, 93], as well as of low field magnetic stimulation (LFMS) $[94,95]$. Additionally, vagus nerve stimulation (VNS) has been cleared by the FDA for TRD [96-98]. As a comprehensive approach of different neuromodulation techniques for TRD is beyond the scope of this review, please see the aforementioned references for further information. 


\section{Challenges}

\section{Stimulation target}

One important area that requires clarification is the identification and engagement of the stimulation target. The field has progressively moved from a simple, anatomically based targeting method, to coil placement based upon individual skull anatomy (Beam F3) [99]. Within the last several years, there is an increasing body of evidence indicating that functional connectivity relationships between the subgenual anterior cingulate (sgACC) and DLPFC may be able to

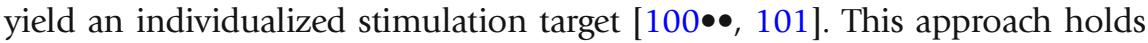
the promise of improving clinical outcomes. Major challenges in this space will be prospectively testing whether these imaging methods can provide superior outcomes to standard of care targeting, and whether the improvements gained are sufficiently robust to outweigh the real-world cost of employing these technically advanced approaches.

"Accelerated TMS" has been the subject of considerable attention. This approach includes the administration of many TMS sessions throughout the day, with the general idea to provide an entire course of TMS to a patient in a few days, as opposed to 6-8 weeks. Holtzheimer et al. performed the first study in this space, and administered 15 low-dose rTMS sessions over 2 days, and found fair response and remission rates [102]. Two crossover studies (Baeken et al. [103] and Desmyeter et al [104]) found accelerated TMS to be safe and feasible, and a recent clinic-based study compared once daily vs. twice daily TMS although found no group differences [105••]. Most recently, a small unblinded study by Cole et al. indicated that iTBS could be administered many times over a single day [106]. In this study, 19 patients received TBS $(1,800$ pulses per session, 50-min intersession interval, 90\% MT adjusted for cortical depth) for 10 sessions daily and targeted to the DLPFC using functional neuroimaging. They reported very high remission rates $(n=19 ; 86.4 \%)$, although loss of efficacy at 1 month. If replicated in a randomized controlled trial, this holds significant promise as a new TRD treatment.

Predictors of response: biomarkers

TMS is very effective, yet costly in the real world; it required significant financial and time commitment from the patient and providers. Over the last decade, there has been significant interest in developing predictors of response. It is important to note that the vast majority of identified predictors have largely been unsuccessful in their goal. For example, patient-level predictors, such as treatment resistance, age, and sex, all have been associated with TMS response (or lack thereof) [107-109], with later data either refuting or at least indicating difficulty replicating these findings (for a comprehensive review, please see $[110 \bullet, 111])$. To this end, we highlight a few of the more recent advances in predictor development, with a focus on biomarkers-biological markers that can predict or characterize treatment response. We acknowledge that nonreplication is also a feature of this literature $($ e.g., $[112,113 \bullet \bullet])$ and provide the below as examples. 


\section{Neuroimaging}

Several studies have suggested that functional neuroimaging may provide patterns of connectivity associated with TMS response (for a review, please see [114]). The most notable and consistent change associated with rTMS across studies is in the Default Mode Network [115, 116•, 117, 118]. Also notable are studies that use clustering and machine learning algorithms to identify brain-based variants of depression [119•]. This approach can lead to finding specific sub-types of depression, with network properties associated with TMS response. The most immediate use of this research has to help identify improved ways to target rTMS.

\section{Electrophysiological}

Recent studies have used EEG to track TMS-emergent changes in cortical networks. EEG interpretation can be complicated and unintuitive as this signal is complex, is time varying, and has low spatial resolution, and there has been little success in finding clear EEG biomarkers for depression [120•]. Machine learning and other data-driven approaches of value analyze and extract salient features of EEG data to identify predictors and mechanisms of treatment. This approach has been used in several recent studies, where EEG-based functional connectivity can identify and predict clinical outcomes [121, 122]. Although these methods show promise, further studies need to validate the outcomes and standardize the approach. EEG holds potential for clinical use, as it is more available and implementable in clinical settings.

\section{Neuroimmunoendocrine}

The immune system and inflammatory pathways play a significant role in the pathobiology of depression. One simplistic example is interferon- $\alpha$, which is used to treat medical illness; interferon- $\alpha$ can induce depressive symptoms, and these symptoms are response to pharmacotherapy (reviewed in [123]). Interestingly, studies that have measured cytokines during rTMS response found reversal of the inflammation after rTMS, and one sham-controlled study reported a significant drop in proinflammatory cytokines in the active rTMS group [124••].

To summarize, multiple candidate biomarkers may inform TMS treatment, if replicated. However, for these approaches to be incorporated clinically, they will need to demonstrate reliability, cost-effectiveness, and a meaningful change in clinical response likelihood. As a result, more clinically usable tools need to be developed, and their performance will need to be evaluated in a naturalistic and real-world clinical settings.

\section{Special section: rTMS during COVID-19 pandemic}

The COVID-19 pandemic has inflicted grave consequences on the world, requiring drastic adaptation of clinical care and research, and neuromodulation guidelines have adapted to meet new safety requirements. In addition to adopting best practices (e.g., Center for Disease Control and Prevention recommendations including social distancing, protective personal equipment), special attention can be given to the type of TMS modality applied. For example, various clinics have shifted from standard rTMS to iTBS. As noted above, iTBS has the benefit of 


\section{Conclusions}

being delivered in a few minutes, which provides significantly less exposure between patients and staff, as well as permitting extra time for cleaning. Recently, a group of experts proposed a set of good practices and recommendations for NIBS in the course of the COVID-19 pandemic and for possible future widespread disease outbreaks. Please see reference [125] for further discussion. The pandemic has also reminded the field that the current model of brain stimulation requires regular visits to healthcare settings. This limitation hinders the impact of these interventions, and poses additional risk during pandemic. It is our hope that the current situation prompts the field to revisit the possibility of technologies that permit home use or minimize regular healthcare visits.

In closing, this review of rTMS for TRD confirms the effectiveness of this technique in improving depressive symptoms, with potential long-lasting effects. Remission occurs on average in one-third of TRD patients, indicating the realworld impact of rTMS. The neurobiological effects of rTMS can be attributed to the direct stimulation of prefrontal areas, with clinical improvement mediated by transsynaptic mechanisms. Regarding different rTMS protocols, the majority of work done to date applied HF-rTMS over the left DLPFC, followed, in order of frequency, by trials delivering LF-rTMS to the right PFC, and fewer using bilateral stimulation. In the last several years, new approaches have emerged, and include dTMS and iTBS, with evidence of efficacy of both techniques, although it remains unclear if any one approach is superior. Furthermore, novel targeting and application procedures continue to develop, each with significant promise to change clinical care. In the setting of the current COVID-19 pandemic, iTBS has gained increased attention for its time-efficient profile, minimizing the chance of exposure. As a final note, in spite of the robust evidence showing rTMS effectiveness, additional studies are needed in order to further investigate predictors of response, potential biomarkers, and the optimal stimulation parameters for TRD.

\section{Funding}

This work was supported in part by VA grants I01 RX002450 \& I01 HX002572, NIH grants R01 MH120126, R25 MH101076, P20 GM130452, and the VA RR\&D Center for Neurorestoration and Neurotechnology at the Providence VA Medical Center.

\section{Declarations}

\section{Conflict of interest}

The views expressed in this article are those of the authors and do not necessarily reflect the position or policy of the Department of Veterans Affairs or the National Institute of Health. The funders had no role in the design of the study, data analysis, or decision to publish this paper. The authors have no relevant biomedical conflicts of interest to disclose. 
Open Access This article is licensed under a Creative Commons Attribution 4.0 International License, which permits use, sharing, adaptation, distribution and reproduction in any medium or format, as long as you give appropriate credit to the original author(s) and the source, provide a link to the Creative Commons licence, and indicate if changes were made. The images or other third party material in this article are included in the article's Creative Commons licence, unless indicated otherwise in a credit line to the material. If material is not included in the article's Creative Commons licence and your intended use is not permitted by statutory regulation or exceeds the permitted use, you will need to obtain permission directly from the copyright holder. To view a copy of this licence, visit http://creativecommons.org/licenses/by/4.0/.

\section{References}

Papers of particular interest, published recently, have been highlighted as:

- Of importance

$\bullet \quad$ Of major importance

1. Whiteford HA, Degenhardt L, Rehm J, Baxter AJ, Ferrari AJ, Erskine HE, et al. Global burden of disease attributable to mental and substance use disorders: findings from the Global Burden of Disease Study 2010. Lancet. 2013;382(9904):1575-86. https://doi.org/10.1016/ S0140-6736(13)61611-6.

2. Murray CJ, Atkinson C, Bhalla K, Birbeck G, Burstein R, Chou D, et al. The state of US health, 1990-2010: burden of diseases, injuries, and risk factors. JAMA. 2013;310(6):591-608. https://doi.org/10.1001/jama. 2013.13805 .

3. Murray CJ, Vos T, Lozano R, Naghavi M, Flaxman AD, Michaud C, et al. Disability-adjusted life years (DALYs) for 291 diseases and injuries in 21 regions, 1990-2010: a systematic analysis for the Global Burden of Disease Study 2010. Lancet. 2012;380(9859):2197-223. https://doi.org/10.1016/S0140-6736(12)61689-4.

4. Disease GBD, Injury I, Prevalence C. Global, regional, and national incidence, prevalence, and years lived with disability for 354 diseases and injuries for 195 countries and territories, 1990-2017: a systematic analysis for the Global Burden of Disease Study 2017. Lancet. 2018;392(10159):1789-858. https://doi.org/ 10.1016/S0140-6736(18)32279-7.

5. Hasin DS, Sarvet AL, Meyers JL, Saha TD, Ruan WJ, Stohl M, et al. Epidemiology of adult DSM-5 major depressive disorder and its specifiers in the United States. JAMA Psychiatry. 2018;75(4):336-46. https:// doi.org/10.1001/jamapsychiatry.2017.4602.

6. Rush AJ, Trivedi MH, Wisniewski SR, Nierenberg AA, Stewart JW, Warden D, et al. Acute and longer-term outcomes in depressed outpatients requiring one or several treatment steps: a STAR*D report. Am J Psychiatry. 2006;163(11):1905-17. https://doi.org/10.1176/ ajp.2006.163.11.1905.

7. Arroll B, Elley CR, Fishman T, Goodyear-Smith FA, Kenealy T, Blashki G, et al. Antidepressants versus placebo for depression in primary care. Cochrane Database Syst Rev. 2009;3:CD007954. https://doi.org/10. 1002/14651858.CD007954.
8. Chou YH, Hickey PT, Sundman M, Song AW, Chen NK. Effects of repetitive transcranial magnetic stimulation on motor symptoms in Parkinson disease: a systematic review and meta-analysis. JAMA Neurol. 2015;72(4):432-40. https://doi.org/10.1001/ jamaneurol.2014.4380.

9. Klomjai W, Katz R, Lackmy-Vallee A. Basic principles of transcranial magnetic stimulation (TMS) and repetitive TMS (rTMS). Ann Phys Rehabil Med. 2015;58(4):20813. https://doi.org/10.1016/j.rehab.2015.05.005.

10. Voigt J, Carpenter L, Leuchter A. Cost effectiveness analysis comparing repetitive transcranial magnetic stimulation to antidepressant medications after a first treatment failure for major depressive disorder in newly diagnosed patients - a lifetime analysis. PLoS One. 2017;12(10):e0186950. https://doi.org/10. 1371/journal.pone.0186950.

$11 . \bullet$ Voigt J, Carpenter L, Leuchter A. A systematic literature review of the clinical efficacy of repetitive transcranial magnetic stimulation (rTMS) in non-treatment resistant patients with major depressive disorder. BMC Psychiatry. 2019;19(1):13. https://doi.org/10.1186/ s12888-018-1989-zComprehensive and recent review of rTMS in non-treatment-resistant individuals.

12. Chail A, Saini RK, Bhat PS, Srivastava K, Chauhan V. Transcranial magnetic stimulation: a review of its evolution and current applications. Ind Psychiatry J. 2018;27(2):172-80. https://doi.org/10.4103/ipj.ipj_ 88_18.

13. Durmaz O, Ates MA, Senol MG. Repetitive transcranial magnetic stimulation (rTMS)-induced trigeminal autonomic cephalalgia. Noro Psikiyatr Ars. 2015;52(3):309-11. https://doi.org/10.5152/npa. 2015.7618.

14. Kozel FA, George MS, Simpson KN. Decision analysis of the cost-effectiveness of repetitive transcranial magnetic stimulation versus electroconvulsive therapy for treatment of nonpsychotic severe depression. CNS Spectr. 2004;9(6):476-82. 
15. Post RM, Kimbrell TA, McCann UD, Dunn RT, Osuch EA, Speer AM, et al. Repetitive transcranial magnetic stimulation as a neuropsychiatric tool: present status and future potential. J ECT. 1999;15(1):39-59.

16. Slotema CW, Blom JD, Hoek HW, Sommer IE. Should we expand the toolbox of psychiatric treatment methods to include repetitive transcranial magnetic stimulation (rTMS)? A meta-analysis of the efficacy of rTMS in psychiatric disorders. J Clin Psychiatry. 2010;71(7):873-84. https://doi.org/10.4088/JCP. 08m04872gre.

17. Berman RM, Narasimhan M, Sanacora G, Miano AP, Hoffman RE, Hu XS, et al. A randomized clinical trial of repetitive transcranial magnetic stimulation in the treatment of major depression. Biol Psychiatry. 2000;47(4):332-7. https://doi.org/10.1016/s00063223(99)00243-7.

18. Brakemeier EL, Luborzewski A, Danker-Hopfe H, Kathmann N, Bajbouj M. Positive predictors for antidepressive response to prefrontal repetitive transcranial magnetic stimulation (rTMS). J Psychiatr Res. 2007;41(5):395-403. https://doi.org/10.1016/j. jpsychires.2006.01.013.

19. George MS, Lisanby SH, Avery D, McDonald WM, Durkalski V, Pavlicova M, et al. Daily left prefrontal transcranial magnetic stimulation therapy for major depressive disorder: a sham-controlled randomized trial. Arch Gen Psychiatry. 2010;67(5):507-16. https:// doi.org/10.1001/archgenpsychiatry.2010.46.

20. Padberg F, Zwanzger P, Keck ME, Kathmann N, Mikhaiel P, Ella R, et al. Repetitive transcranial magnetic stimulation (rTMS) in major depression: relation between efficacy and stimulation intensity. Neuropsychopharmacology. 2002;27(4):638-45. https://doi. org/10.1016/S0893-133X(02)00338-X.

21. Pascual-Leone A, Rubio B, Pallardo F, Catala MD. Rapid-rate transcranial magnetic stimulation of left dorsolateral prefrontal cortex in drug-resistant depression. Lancet. 1996;348(9022):233-7. https://doi.org/ 10.1016/s0140-6736(96)01219-6.

22. Drevets WC. Functional anatomical abnormalities in limbic and prefrontal cortical structures in major depression. Prog Brain Res. 2000;126:413-31. https:// doi.org/10.1016/S0079-6123(00)26027-5.

23. Grimm S, Beck J, Schuepbach D, Hell D, Boesiger P, Bermpohl F, et al. Imbalance between left and right dorsolateral prefrontal cortex in major depression is linked to negative emotional judgment: an fMRI study in severe major depressive disorder. Biol Psychiatry. 2008;63(4):369-76. https://doi.org/10.1016/j. biopsych.2007.05.033.

24. Drevets WC, Price JL, Simpson JR Jr, Todd RD, Reich T, Vannier $\mathrm{M}$, et al. Subgenual prefrontal cortex abnormalities in mood disorders. Nature. 1997;386(6627):824-7. https://doi.org/10.1038/ 386824a0.

25. Pellicciari MC, Cordone S, Marzano C, Bignotti S, Gazzoli A, Miniussi C, et al. Dorsolateral prefrontal transcranial magnetic stimulation in patients with major depression locally affects alpha power of REM sleep. Front Hum Neurosci. 2013;7:433. https://doi. org/10.3389/fnhum.2013.00433.

26. Fitzgerald PB, Hoy K, Gunewardene R, Slack C, Ibrahim S, Bailey $\mathrm{M}$, et al. A randomized trial of unilateral and bilateral prefrontal cortex transcranial magnetic stimulation in treatment-resistant major depression. Psychol Med. 2011;41(6):1187-96. https://doi.org/10. 1017/S0033291710001923.

27. Mayberg HS, Brannan SK, Tekell JL, Silva JA, Mahurin RK, McGinnis S, et al. Regional metabolic effects of fluoxetine in major depression: serial changes and relationship to clinical response. Biol Psychiatry. 2000;48(8):830-43. https://doi.org/10.1016/s00063223(00)01036-2.

28. Dunlop K, Talishinsky A, Liston C. Intrinsic brain network biomarkers of antidepressant response: a review. Curr Psychiatry Rep. 2019;21(9):87. https://doi.org/ 10.1007/s11920-019-1072-6Important review of brain network markers of broad utility to antidepressant response.

29. Furman DJ, Hamilton JP, Gotlib IH. Frontostriatal functional connectivity in major depressive disorder. Biol Mood Anxiety Disord. 2011;1(1):11. https://doi. org/10.1186/2045-5380-1-11.

30. Philippi CL, Motzkin JC, Pujara MS, Koenigs M. Subclinical depression severity is associated with distinct patterns of functional connectivity for subregions of anterior cingulate cortex. J Psychiatr Res. 2015;71:10311. https://doi.org/10.1016/j.jpsychires.2015.10.005.

31. Sheline YI, Price JL, Yan Z, Mintun MA. Resting-state functional MRI in depression unmasks increased connectivity between networks via the dorsal nexus. Proc Natl Acad Sci U S A. 2010;107(24):11020-5. https:// doi.org/10.1073/pnas.1000446107.

32. Bestmann S, Swayne O, Blankenburg F, Ruff CC, Haggard $\mathrm{P}$, Weiskopf $\mathrm{N}$, et al. Dorsal premotor cortex exerts state-dependent causal influences on activity in contralateral primary motor and dorsal premotor cortex. Cereb Cortex. 2008;18(6):1281-91. https://doi.org/ $10.1093 /$ cercor/bhm159.

33. Massimini M, Ferrarelli F, Huber R, Esser SK, Singh H, Tononi G. Breakdown of cortical effective connectivity during sleep. Science. 2005;309(5744):2228-32. https://doi.org/10.1126/science.1117256.

34. Siebner HR, Hartwigsen G, Kassuba T, Rothwell JC. How does transcranial magnetic stimulation modify neuronal activity in the brain? Implications for studies of cognition. Cortex. 2009;45(9):1035-42. https://doi. org/10.1016/j.cortex.2009.02.007.

35. Baeken C, De Raedt R. Neurobiological mechanisms of repetitive transcranial magnetic stimulation on the underlying neurocircuitry in unipolar depression. Dialogues Clin Neurosci. 2011;13(1):139-45.

36. Speer AM, Kimbrell TA, Wassermann EM. J DR, Willis MW, Herscovitch P et al. Opposite effects of high and low frequency rTMS on regional brain activity in depressed patients. Biol Psychiatry. 2000;48(12):113341. https://doi.org/10.1016/s0006-3223(00)01065-9. 
37. George MS, Nahas Z, Molloy M, Speer AM, Oliver NC, $\mathrm{Li} \mathrm{XB}$, et al. A controlled trial of daily left prefrontal cortex TMS for treating depression. Biol Psychiatry. 2000;48(10):962-70. https://doi.org/10.1016/s00063223(00)01048-9.

38. George MS, Wassermann EM, Kimbrell TA, Little JT, Williams WE, Danielson AL, et al. Mood improvement following daily left prefrontal repetitive transcranial magnetic stimulation in patients with depression: a placebo-controlled crossover trial. Am J Psychiatry. 1997;154(12):1752-6. https://doi.org/10.1176/ajp. 154.12.1752.

39. Klein E, Kreinin I, Chistyakov A, Koren D, Mecz L, Marmur S, et al. Therapeutic efficacy of right prefrontal slow repetitive transcranial magnetic stimulation in major depression: a double-blind controlled study. Arch Gen Psychiatry. 1999;56(4):315-20. https://doi. org/10.1001/archpsyc.56.4.315.

40. Padberg F, Zwanzger P, Thoma H, Kathmann N, Haag $\mathrm{C}$, Greenberg BD, et al. Repetitive transcranial magnetic stimulation (rTMS) in pharmacotherapy-refractory major depression: comparative study of fast, slow and sham rTMS. Psychiatry Res. 1999;88(3):163-71. https://doi.org/10.1016/s0165-1781(99)00092-x.

41. Garcia-Toro M, Mayol A, Arnillas H, Capllonch I, Ibarra $\mathrm{O}$, Crespi $\mathrm{M}$, et al. Modest adjunctive benefit with transcranial magnetic stimulation in medicationresistant depression. J Affect Disord. 2001;64(23):271-5. https://doi.org/10.1016/s0165-0327(00) 00223-8.

42. Loo C, Mitchell P, Sachdev P, McDarmont B, Parker G, Gandevia S. Double-blind controlled investigation of transcranial magnetic stimulation for the treatment of resistant major depression. Am J Psychiatry. 1999;156(6):946-8. https://doi.org/10.1176/ajp.156. 6.946.

43. Manes F, Jorge R, Morcuende M, Yamada T, Paradiso S, Robinson RG. A controlled study of repetitive transcranial magnetic stimulation as a treatment of depression in the elderly. Int Psychogeriatr. 2001;13(2):22531. https://doi.org/10.1017/s1041610201007608.

44. Perera T, George MS, Grammer G, Janicak PG, PascualLeone A, Wirecki TS. The Clinical TMS Society Consensus Review and Treatment Recommendations for TMS therapy for major depressive disorder. Brain Stimul. 2016;9(3):336-46. https://doi.org/10.1016/j. brs.2016.03.010.

45. Deng ZD, Lisanby SH, Peterchev AV. Electric field depth-focality tradeoff in transcranial magnetic stimulation: simulation comparison of 50 coil designs. Brain Stimul. 2013;6(1):1-13. https://doi.org/10.1016/j.brs. 2012.02.005.

46. Gomez LJ, Goetz SM, Peterchev AV. Design of transcranial magnetic stimulation coils with optimal tradeoff between depth, focality, and energy. J Neural Eng. 2018;15(4):046033. https://doi.org/10.1088/17412552/aac967Important article describing the depth/ focality trade-off and how this influences coil design.
47. O'Reardon JP, Solvason HB, Janicak PG, Sampson S, Isenberg KE, Nahas Z, et al. Efficacy and safety of transcranial magnetic stimulation in the acute treatment of major depression: a multisite randomized controlled trial. Biol Psychiatry. 2007;62(11):120816. https://doi.org/10.1016/j.biopsych.2007.01.018.

48. Berlim MT, Van den Eynde F, Jeff DZ. Clinically meaningful efficacy and acceptability of low-frequency repetitive transcranial magnetic stimulation (rTMS) for treating primary major depression: a meta-analysis of randomized, double-blind and sham-controlled trials. Neuropsychopharmacology. 2013;38(4):543-51. https://doi.org/10.1038/npp.2012.237.

49. Zhang YQ, Zhu D, Zhou XY, Liu YY, Qin B, Ren GP, et al. Bilateral repetitive transcranial magnetic stimulation for treatment-resistant depression: a systematic review and meta-analysis of randomized controlled trials. Braz J Med Biol Res. 2015;48(3):198-206. https://doi.org/10.1590/1414-431X20144270.

$50 . \bullet$ Sackeim HA, Aaronson ST, Carpenter LL, Hutton TM, Mina M, Pages K, et al. Clinical outcomes in a large registry of patients with major depressive disorder treated with transcranial magnetic stimulation. J Affect Disord. 2020;277:65-74. https://doi.org/10.1016/j. jad.2020.08.005Largest registry study to date describing naturalistic TMS outcomes.

51. Larson J, Munkacsy E. Theta-burst LTP. Brain Res. 2015;1621:38-50. https://doi.org/10.1016/j.brainres. 2014.10.034

52.• Blumberger DM, Vila-Rodriguez F, Thorpe KE, Feffer K, Noda Y, Giacobbe P, et al. Effectiveness of theta burst versus high-frequency repetitive transcranial magnetic stimulation in patients with depression (THREE-D): a randomised non-inferiority trial. Lancet. 2018;391(10131):1683-92. https://doi.org/10.1016/ S0140-6736(18)30295-2Large multisite noninferiority study of theta burst TMS for depression.

53. George MS, Wassermann EM, Williams WA, Callahan A, Ketter TA, Basser P, et al. Daily repetitive transcranial magnetic stimulation (rTMS) improves mood in depression. Neuroreport. 1995;6(14):1853-6. https:// doi.org/10.1097/00001756-199510020-00008.

54. Abarbanel JM, Lemberg T, Yaroslavski U, Grisaru N, Belmaker RH. Electrophysiological responses to transcranial magnetic stimulation in depression and schizophrenia. Biol Psychiatry. 1996;40(2):148-50. https://doi.org/10.1016/0006-3223(95)00664-8.

55. SKAHSRHJM GH. Application of transcranial magnetic stimulation in treatment of drug-resistant major depression-a report of two cases. Hum Psychopharmacol Clin Exp. 1993;8:361-5.

56. Carpenter LL, Janicak PG, Aaronson ST, Boyadjis T, Brock DG, Cook IA, et al. Transcranial magnetic stimulation (TMS) for major depression: a multisite, naturalistic, observational study of acute treatment outcomes in clinical practice. Depress Anxiety. 2012;29(7):587-96. https://doi.org/10.1002/da. 21969. 
57. Avery DH, Isenberg KE, Sampson SM, Janicak PG, Lisanby SH, Maixner DF, et al. Transcranial magnetic stimulation in the acute treatment of major depressive disorder: clinical response in an open-label extension trial. J Clin Psychiatry. 2008;69(3):441-51. https://doi. org/10.4088/jcp.v69n0315.

58. Demitrack MA, Thase ME. Clinical significance of transcranial magnetic stimulation (TMS) in the treatment of pharmacoresistant depression: synthesis of recent data. Psychopharmacol Bull. 2009;42(2):5-38.

59. McDonald WM, Durkalski V, Ball ER, Holtzheimer PE, Pavlicova M, Lisanby $\mathrm{SH}$, et al. Improving the antidepressant efficacy of transcranial magnetic stimulation: maximizing the number of stimulations and treatment location in treatment-resistant depression. Depress Anxiety. 2011;28(11):973-80. https://doi.org/10. 1002/da.20885.

60. Levkovitz Y, Harel EV, Roth Y, Braw Y, Most D, Katz LN, et al. Deep transcranial magnetic stimulation over the prefrontal cortex: evaluation of antidepressant and cognitive effects in depressive patients. Brain Stimul. 2009;2(4):188-200. https://doi.org/10.1016/j.brs. 2009.08.002.

61. Roth Y, Zangen A, Hallett M. A coil design for transcranial magnetic stimulation of deep brain regions. J Clin Neurophysiol. 2002;19(4):361-70. https://doi. org/10.1097/00004691-200208000-00008.

62. Roth Y, Amir A, Levkovitz Y, Zangen A. Threedimensional distribution of the electric field induced in the brain by transcranial magnetic stimulation using figure- 8 and deep H-coils. J Clin Neurophysiol. 2007;24(1):31-8. https://doi.org/10.1097/WNP. ob013e31802fa393.

63. Zangen A, Roth Y, Voller B, Hallett M. Transcranial magnetic stimulation of deep brain regions: evidence for efficacy of the H-coil. Clin Neurophysiol. 2005;116(4):775-9. https://doi.org/10.1016/j.clinph. 2004.11.008.

64. Levkovitz $\mathrm{Y}$, Isserles $\mathrm{M}$, Padberg F, Lisanby SH, Bystritsky A, Xia G, et al. Efficacy and safety of deep transcranial magnetic stimulation for major depression: a prospective multicenter randomized controlled trial. World Psychiatry. 2015;14(1):64-73. https://doi.org/ 10.1002/wps.20199.

65. Filipcic I, Simunovic Filipcic I, Milovac Z, Sucic S, Gajsak T, Ivezic E, et al. Efficacy of repetitive transcranial magnetic stimulation using a figure-8-coil or an $\mathrm{H} 1$-coil in treatment of major depressive disorder; A randomized clinical trial. J Psychiatr Res. 2019;114:113-9. https://doi.org/10.1016/j.jpsychires. 2019.04.020.

66. Huang YZ, Rothwell JC. The effect of short-duration bursts of high-frequency, low-intensity transcranial magnetic stimulation on the human motor cortex. Clin Neurophysiol. 2004;115(5):1069-75. https://doi.org/ 10.1016/j.clinph.2003.12.026.

67. Mendlowitz AB, Shanbour A, Downar J, Vila-Rodriguez F, Daskalakis ZJ, Isaranuwatchai W, et al. Implementation of intermittent theta burst stimulation compared to conventional repetitive transcranial magnetic stimulation in patients with treatment resistant depression: a cost analysis. PLoS One.

2019;14(9):e0222546. https://doi.org/10.1371/ journal.pone.0222546.

68. Huang YZ, Edwards MJ, Rounis E, Bhatia KP, Rothwell JC. Theta burst stimulation of the human motor cortex. Neuron. 2005;45(2):201-6. https://doi.org/10.1016/j. neuron.2004.12.033.

69. Li CT, Chen MH, Juan CH, Huang HH, Chen LF, Hsieh JC, et al. Efficacy of prefrontal theta-burst stimulation in refractory depression: a randomized shamcontrolled study. Brain. 2014;137(Pt 7):2088-98. https://doi.org/10.1093/brain/awu109.

70. Avery DH, Holtzheimer PE 3rd, Fawaz W, Russo J, Neumaier J, Dunner DL, et al. A controlled study of repetitive transcranial magnetic stimulation in medication-resistant major depression. Biol Psychiatry. 2006;59(2):187-94. https://doi.org/10.1016/j. biopsych.2005.07.003.

71. Fitzgerald PB, Brown TL, Marston NA, Daskalakis ZJ, De Castella A, Kulkarni J. Transcranial magnetic stimulation in the treatment of depression: a double-blind, placebo-controlled trial. Arch Gen Psychiatry. 2003;60(10):1002-8. https://doi.org/10.1001/ archpsyc.60.9.1002.

72. Fitzgerald PB, Hoy K, Daskalakis ZJ, Kulkarni J. A randomized trial of the anti-depressant effects of low- and high-frequency transcranial magnetic stimulation in treatment-resistant depression. Depress Anxiety. 2009;26(3):229-34. https://doi.org/10.1002/da. 20454.

73. Fitzgerald PB, Benitez J, de Castella A, Daskalakis ZJ, Brown TL, Kulkarni J. A randomized, controlled trial of sequential bilateral repetitive transcranial magnetic stimulation for treatment-resistant depression. Am J Psychiatry. 2006;163(1):88-94. https://doi.org/10. 1176/appi.ajp.163.1.88.

74. Blumberger DM, Maller JJ, Thomson L, Mulsant BH, Rajji TK, Maher M, et al. Unilateral and bilateral MRItargeted repetitive transcranial magnetic stimulation for treatment-resistant depression: a randomized controlled study. J Psychiatry Neurosci. 2016;41(4):E5866. https://doi.org/10.1503/jpn.150265.

75. Fitzgerald PB, Hoy KE, Singh A, Gunewardene R, Slack C, Ibrahim S, et al. Equivalent beneficial effects of unilateral and bilateral prefrontal cortex transcranial magnetic stimulation in a large randomized trial in treatment-resistant major depression. Int J Neuropsychopharmacol. 2013;16(9):1975-84. https://doi.org/ $10.1017 /$ S1461145713000369.

76. Fitzgerald PB, Hoy KE, Herring SE, McQueen S, Peachey AV, Segrave RA, et al. A double blind randomized trial of unilateral left and bilateral prefrontal cortex transcranial magnetic stimulation in treatment resistant major depression. J Affect Disord. 2012;139(2):193-8. https://doi.org/10.1016/j.jad. 2012.02.017. 
77.• Brunoni AR, Chaimani A, Moffa AH, Razza LB, Gattaz WF, Daskalakis ZJ, et al. Repetitive transcranial magnetic stimulation for the acute treatment of major depressive episodes: a systematic review with network meta-analysis. JAMA Psychiatry. 2017;74(2):143-52. https://doi.org/10.1001/jamapsychiatry.2016. 3644 Network meta-analysis evaluating various TMS treatment options.

78.• Berlow YA, Zandvakili A, Philip NS. Low frequency right-sided and high frequency left-sided repetitive transcranial magnetic stimulation for depression: the evidence of equivalence. Brain Stimul. 2020;13(6):1793-5. https://doi.org/10.1016/j.brs. 2020.10.005Important piece indicating limited differences between stimulation location and parameters.

79. Dunner DL, Aaronson ST, Sackeim HA, Janicak PG, Carpenter LL, Boyadjis T, et al. A multisite, naturalistic, observational study of transcranial magnetic stimulation for patients with pharmacoresistant major depressive disorder: durability of benefit over a 1-year follow-up period. J Clin Psychiatry. 2014;75(12):1394-401. https://doi.org/10.4088/JCP. $13 \mathrm{~m} 08977$.

80. Janicak PG, Nahas Z, Lisanby SH, Solvason HB, Sampson SM, McDonald WM, et al. Durability of clinical benefit with transcranial magnetic stimulation (TMS) in the treatment of pharmacoresistant major depression: assessment of relapse during a 6-month, multisite, open-label study. Brain Stimul.

2010;3(4):187-99. https://doi.org/10.1016/j.brs. 2010.07.003.

81. Mantovani A, Pavlicova M, Avery D, Nahas Z, McDonald WM, Wajdik CD, et al. Long-term efficacy of repeated daily prefrontal transcranial magnetic stimulation (TMS) in treatment-resistant depression. Depress Anxiety. 2012;29(10):883-90. https://doi.org/ 10.1002/da.21967.

82. Arul-Anandam AP, Loo C. Transcranial direct current stimulation: a new tool for the treatment of depression? J Affect Disord. 2009;117(3):137-45. https://doi. org/10.1016/j.jad.2009.01.016.

83. Brunoni AR. tDCS in depression: quo usque tandem? J Affect Disord. 2019;256:431-2. https://doi.org/10. 1016/j.jad.2019.06.020.

84. Brunoni AR, Moffa AH, Fregni F, Palm U, Padberg F, Blumberger DM, et al. Transcranial direct current stimulation for acute major depressive episodes: metaanalysis of individual patient data. Br J Psychiatry. 2016;208(6):522-31. https://doi.org/10.1192/bjp.bp. 115.164715 .

85. Cretaz E, Brunoni AR, Lafer B. Magnetic seizure therapy for unipolar and bipolar depression: a systematic review. Neural Plast. 2015;2015:521398. https://doi.org/ $10.1155 / 2015 / 521398$.

86. Hoy KE, Thomson RH, Cherk M, Yap KS, Daskalakis ZJ, Fitzgerald PB. Effect of magnetic seizure therapy on regional brain glucose metabolism in major depression. Psychiatry Res. 2013;211(2):169-75. https://doi.org/10.1016/j.pscychresns.2012.08.003.

87. Kayser S, Bewernick BH, Grubert C, Hadrysiewicz BL, Axmacher N, Schlaepfer TE. Antidepressant effects, of magnetic seizure therapy and electroconvulsive therapy, in treatment-resistant depression. J Psychiatr Res. 2011;45(5):569-76. https://doi.org/10.1016/j. jpsychires.2010.09.008.

88. Lisanby SH, Luber B, Schlaepfer TE, Sackeim HA. Safety and feasibility of magnetic seizure therapy (MST) in major depression: randomized within-subject comparison with electroconvulsive therapy. Neuropsychopharmacology. 2003;28(10):1852-65. https://doi.org/ 10.1038/sj.npp.1300229.

89. Cassano P, Petrie SR, Mischoulon D, Cusin C, Katnani $\mathrm{H}$, Yeung A, et al. Transcranial photobiomodulation for the treatment of major depressive disorder. The ELATED-2 Pilot Trial. Photomed Laser Surg. 2018;36(12):634-46. https://doi.org/10.1089/pho. 2018.4490.

90. Schiffer F, Johnston AL, Ravichandran C, Polcari A, Teicher MH, Webb RH, et al. Psychological benefits 2 and 4 weeks after a single treatment with near infrared light to the forehead: a pilot study of 10 patients with major depression and anxiety. Behav Brain Funct. 2009;5:46. https://doi.org/10.1186/1744-9081-5-46.

91. Mooney SJ, Nobrega JN, Levitt AJ, Hynynen K. Antidepressant effects of focused ultrasound induced blood-brain-barrier opening. Behav Brain Res. 2018;342:57-61. https://doi.org/10.1016/j.bbr.2018. 01.004 .

92. Tsai SJ. Transcranial focused ultrasound as a possible treatment for major depression. Med Hypotheses. 2015;84(4):381-3. https://doi.org/10.1016/j.mehy. 2015.01.030.

93. Dubin MJ, Ilieva IP, Deng ZD, Thomas J, Cochran A, Kravets K, et al. A double-blind pilot dosing study of low field magnetic stimulation (LFMS) for treatmentresistant depression (TRD). J Affect Disord. 2019;249:286-93. https://doi.org/10.1016/j.jad.2019. 02.039 .

94. Rohan ML, Yamamoto RT, Ravichandran CT, Cayetano KR, Morales OG, Olson DP, et al. Rapid moodelevating effects of low field magnetic stimulation in depression. Biol Psychiatry. 2014;76(3):186-93. https://doi.org/10.1016/j.biopsych.2013.10.024.

95. Lv H, Zhao YH, Chen JG, Wang DY, Chen H. Vagus nerve stimulation for depression: a systematic review. Front Psychol. 2019;10:64. https://doi.org/10.3389/ fpsyg.2019.00064.

96. Muller HHO, Moeller S, Lucke C, Lam AP, Braun N, Philipsen A. Vagus nerve stimulation (VNS) and other augmentation strategies for therapy-resistant depression (TRD): Review of the Evidence and Clinical Advice for Use. Front Neurosci. 2018;12:239. https://doi.org/ 10.3389/fnins.2018.00239.

97. O'Reardon JP, Cristancho P, Peshek AD. Vagus nerve stimulation (VNS) and treatment of depression: to the brainstem and beyond. Psychiatry. 2006;3(5):54-63. 
98. Beam W, Borckardt JJ, Reeves ST, George MS. An efficient and accurate new method for locating the F3 position for prefrontal TMS applications. Brain Stimul. 2009;2(1):50-4. https://doi.org/10.1016/j.brs.2008. 09.006 .

99. Cash RFH, Cocchi L, Lv J, Fitzgerald PB, Zalesky A. Functional magnetic resonance imaging-guided personalization of transcranial magnetic stimulation treatment for depression. JAMA Psychiatry. 2020. https://doi.org/10.1001/jamapsychiatry.2020.3794.

100.• Weigand A, Horn A, Caballero R, Cooke D, Stern AP, Taylor SF, et al. Prospective validation that subgenual connectivity predicts antidepressant efficacy of transcranial magnetic stimulation sites. Biol Psychiatry. 2018;84(1):28-37. https://doi.org/10.1016/j. biopsych.2017.10.028Prospective testing of subgenual to DLPFC imaging and how it can predict TMS outcomes.

101. Holtzheimer PE 3rd, McDonald WM, Mufti M, Kelley ME, Quinn S, Corso G, et al. Accelerated repetitive transcranial magnetic stimulation for treatmentresistant depression. Depress Anxiety. 2010;27(10):960-3. https://doi.org/10.1002/da. 20731.

102. Baeken C, Vanderhasselt MA, Remue J, Herremans S, Vanderbruggen N, Zeeuws D, et al. Intensive HF-rTMS treatment in refractory medication-resistant unipolar depressed patients. J Affect Disord. 2013;151(2):62531. https://doi.org/10.1016/j.jad.2013.07.008.

103. Desmyter S, Duprat R, Baeken C, Van Autreve S, Audenaert K, van Heeringen K. Accelerated intermittent theta burst stimulation for suicide risk in therapyresistant depressed patients: a randomized, shamcontrolled trial. Front Hum Neurosci. 2016;10:480. https://doi.org/10.3389/fnhum.2016.00480.

104. Fitzgerald PB, Hoy KE, Elliot D, McQueen S, Wambeek LE, Daskalakis ZJ. Exploring alternative rTMS strategies in non-responders to standard high frequency left-sided treatment: a switching study. J Affect Disord. 2018;232:79-82. https://doi.org/10.1016/j. jad.2018.02.016.

105.• Cole EJ, Stimpson KH, Bentzley BS, Gulser M, Cherian $\mathrm{K}$, Tischler C, et al. Stanford Accelerated Intelligent Neuromodulation Therapy for treatment-resistant depression. Am J Psychiatry. 2020;177(8):716-26. https://doi.org/10.1176/appi.ajp.2019. 19070720 First unblinded study of many TMS sessions per day yielding superior outcomes.

106. Feffer K, Lee HH, Mansouri F, Giacobbe P, VilaRodriguez F, Kennedy SH, et al. Early symptom improvement at 10 sessions as a predictor of rTMS treatment outcome in major depression. Brain Stimul. 2018;11(1):181-9. https://doi.org/10.1016/j. brs.2017.10.010.

107. Fregni F, Marcolin MA, Myczkowski M, Amiaz R, Hasey G, Rumi DO, et al. Predictors of antidepressant response in clinical trials of transcranial magnetic stimulation. Int J Neuropsychopharmacol.
2006;9(6):641-54. https://doi.org/10.1017/ S1461145705006280.

108. Lisanby SH, Husain MM, Rosenquist PB, Maixner D, Gutierrez R, Krystal A, et al. Daily left prefrontal repetitive transcranial magnetic stimulation in the acute treatment of major depression: clinical predictors of outcome in a multisite, randomized controlled clinical trial. Neuropsychopharmacology.

2009;34(2):522-34. https://doi.org/10.1038/npp. 2008.118.

109. Beck QM, Tirrell E, Fukuda AM, Kokdere F, Carpenter LL. Can early treatment response serve as a predictor of antidepressant outcome of repetitive Transcranial Magnetic Stimulation? Brain Stimul.

2020;13(2):420-1. https://doi.org/10.1016/j.brs. 2019.12.002.

110. Kar SK. Predictors of response to repetitive transcranial magnetic stimulation in depression: a review of recent updates. Clin Psychopharmacol Neurosci. 2019;17(1):25-33. https://doi.org/10.9758/cpn. 2019.17.1.25Good review of predictors of response to rTMS.

111. Bailey NW, Krepel N, van Dijk H, Leuchter AF, VilaRodriguez F, Blumberger DM, et al. Resting EEG theta connectivity and alpha power to predict repetitive transcranial magnetic stimulation response in depression: a non-replication from the ICON-DB consortium. Clin Neurophysiol. 2020. https://doi.org/ 10.1016/j.clinph.2020.10.018.

112. Dinga R, Schmaal L, Penninx B, van Tol MJ, Veltman DJ, van Velzen L, et al. Evaluating the evidence for biotypes of depression: methodological replication and extension of. Neuroimage Clin. 2019;22:101796. https://doi.org/10.1016/j.nicl.2019.101796.

113.• Philip NS, Barredo J, Aiken E, Carpenter LL. Neuroimaging Mechanisms of Therapeutic transcranial magnetic stimulation for major depressive disorder. Biol Psychiatry Cogn Neurosci Neuroimaging. 2018;3(3):211-22. https://doi.org/10.1016/j.bpsc. 2017.10.007Review of imaging studies of TMS to describe common findings.

114. Loo CK, Sachdev PS, Haindl W, Wen W, Mitchell PB, Croker VM, et al. High $(15 \mathrm{~Hz})$ and low $(1 \mathrm{~Hz})$ frequency transcranial magnetic stimulation have different acute effects on regional cerebral blood flow in depressed patients. Psychol Med. 2003;33(6):9971006. https://doi.org/10.1017/s0033291703007955.

115. Baeken C, Marinazzo D, Wu GR, Van Schuerbeek P, De Mey J, Marchetti I, et al. Accelerated HF-rTMS in treatment-resistant unipolar depression: insights from subgenual anterior cingulate functional connectivity. World J Biol Psychiatry. 2014;15(4):28697. https://doi.org/10.3109/15622975.2013. 872295.

116.• Philip NS, Barredo J, Van't Wout Frank M, Tyrka AR, Price LH, Carpenter LL. Network mechanisms of clinical response to transcranial magnetic stimulation in posttraumatic stress disorder and major depressive disorder. Biol Psychiatry. 2018;83(3):263-72. https:// 
doi.org/10.1016/j.biopsych.2017.07.

021Neuroimaging study of TMS in commonly patients with common comorbidities.

117. Salomons TV, Dunlop K, Kennedy SH, Flint A, Geraci J, Giacobbe P, et al. Resting-state cortico-thalamicstriatal connectivity predicts response to dorsomedial prefrontal rTMS in major depressive disorder. Neuropsychopharmacology. 2014;39(2):488-98. https:// doi.org/10.1038/npp.2013.222.

118. Drysdale AT, Grosenick L, Downar J, Dunlop K, Mansouri F, Meng Y, et al. Resting-state connectivity biomarkers define neurophysiological subtypes of depression. Nat Med. 2017;23(1):28-38. https://doi. org/10.1038/nm.4246.

119.•• Widge AS, Bilge MT, Montana R, Chang W, Rodriguez CI, Deckersbach T, et al. Electroencephalographic biomarkers for treatment response prediction in major depressive illness: a meta-analysis. Am J Psychiatry. 2019;176(1):44-56. https://doi.org/10.1176/ appi.ajp.2018.17121358Important recent review indicated limited utility of EEG biomarkers in depression.

120.• Zandvakili A, Swearingen HR, Philip NS. Changes in functional connectivity after theta-burst transcranial magnetic stimulation for post-traumatic stress disorder: a machine-learning study. Eur Arch Psychiatry Clin Neurosci. 2020. https://doi.org/10. 1007/s00406-020-01172-5 Important proof of concept study of applied computational psychiatry.

121. Zandvakili A, Philip NS, Jones SR, Tyrka AR, Greenberg BD, Carpenter LL. Use of machine learning in predicting clinical response to transcranial magnetic stimulation in comorbid posttraumatic stress disorder and major depression: a resting state electroencephalography study. J Affect Disord. 2019;252:4754. https://doi.org/10.1016/j.jad.2019.03.077.

122. Raison CL, Capuron L, Miller AH. Cytokines sing the blues: inflammation and the pathogenesis of depression. Trends Immunol. 2006;27(1):24-31. https:// doi.org/10.1016/j.it.2005.11.006.

123. Aftanas LI, Gevorgyan MM, Zhanaeva SY, Dzemidovich SS, Kulikova KI, Al'perina EL, et al. Therapeutic effects of repetitive transcranial magnetic stimulation (rTMS) on neuroinflammation and neuroplasticity in patients with Parkinson's disease: a placebocontrolled study. Bull Exp Biol Med. 2018;165(2):195-9. https://doi.org/10.1007/ s10517-018-4128-4.

124.• Bikson M, Hanlon CA, Woods AJ, Gillick BT, Charvet L, Lamm C, et al. Guidelines for TMS/tES clinical services and research through the COVID-19 pandemic. Brain Stimul. 2020;13(4):1124-49. https:// doi.org/10.1016/j.brs.2020.05.010Helpful guidelines about how to deliver non-invasive brain stimulation during COVID19.

\section{Publisher's Note}

Springer Nature remains neutral with regard to jurisdictional claims in published maps and institutional affiliations. 